\title{
Association of Influenza-Like Illness and Climatic Parameters With Hemoptysis
}

\author{
Ignasi Garcia-Olivé MD, Jose A Fiz MD PhD, Jose Sanz-Santos MD, \\ Carlos Martínez-Rivera MD, Marisol Prats MD, and Juan Ruiz-Manzano MD
}

\begin{abstract}
BACKGROUND: Although some authors have suggested that there is some seasonal periodicity of hemoptysis, or relation to respiratory tract infections, the association of influenza or climatic parameters with hemoptysis has been poorly investigated. Our aim was to describe the relationship between influenza and climatic parameters with severe hemoptysis that required bronchial artery embolization (BAE). METHODS: All consecutive subjects with at least one episode of hemoptysis that required BAE during a 5-y period were included. We applied a general multivariable additive seemingly causal model corresponding to a lagged variable autoregressive model with the exogenous variables as monthly mean temperature, lagged monthly mean temperature $(-1)$, and monthly mean influenza activity, and the number of embolizations as the endogenous variable. RESULTS: We found a significant association between severe hemoptysis requiring BAE and low monthly mean temperature and influenza activity. Other climatic factors, such as atmospheric pressure, rainfall, relative humidity, or wind speed, failed to show significant association with the occurrence of life-threatening hemoptysis. CONCLUSIONS: There is a strong long running relationship between severe hemoptysis and low monthly mean temperature. A weaker association of hemoptysis with influenza activity was also found. Key words: bronchial artery embolization; climatic factors; Google Flu Trends; hemoptysis; influenza; temperature. [Respir Care 2014;59(11):1726-1730. (C) 2014 Daedalus Enterprises]
\end{abstract}

\section{Introduction}

Hemoptysis is a potentially life-threatening situation that requires prompt intervention. Several conditions, such as tuberculosis, cancer, or bronchiectasis, may lead to clini-

Drs Garcia-Olivé, Fiz, Sanz-Santos, Martínez Rivera, Prats, and RuizManzano are affiliated with the Respiratory Service, Hospital Universitari Germans Trias i Pujol, Badalona, Barcelona; Drs Garcia-Olivé, Martínez Rivera, and Ruiz-Manzano, are affiliated with Ciber de Enfermedades Respiratorias, Bunyola, Bunyola, Mallorca; Drs Garcia-Olivé, Sanz-Santos, Martínez Rivera, and Ruiz-Manzano are affiliated with Fundació Institut d'Investigació en Ciències de la Salut Germans Trias i Pujol, Badalona, Barcelona; Dr Ruiz-Manzano is affiliated with Departament de Medicina, Universitat Autònoma de Barcelona, Bellaterra, Spain.

The authors have disclosed no conflicts of interest.

Correspondence: Ignasi Garcia-Olivé MD, Respiratory Service, Hospital Universitari Germans Trias i Pujol, Carretera de Canyet s/n, 08916 Badalona, Barcelona, Spain. E-mail: ignasi.g.olive@gmail.com.

DOI: $10.4187 /$ respcare. 03044 cally important hemoptysis. Although some authors have suggested that there is some seasonal periodicity of hemoptysis, ${ }^{1-3}$ or association with respiratory tract infections, ${ }^{4-6}$ the association of influenza or climatic parameters with life-threatening hemoptysis has been poorly investigated.

Bronchial artery embolization (BAE) is a safe and effective treatment for massive hemoptysis, as well as for chronic but nonmassive hemoptysis that impairs a patient's quality of life or could be a precursor of a massive hemoptysis event. ${ }^{7}$

This paper describes the relationship between influenza and climatic parameters with severe hemoptysis that required bronchial artery embolization.

\section{Methods}

\section{Institution}

This was an observational retrospective study of subjects presenting with life-threatening hemoptysis who un- 
derwent BAE at Hospital Universitari Germans Trias i Pujol, a 600-bed tertiary referral hospital in Badalona (Catalonia, Spain). It is a referral hospital for $>700,000$ people. In 2009, there were 27,000 hospital admissions and 110,000 admissions to the emergency room.

\section{Case Definition}

All consecutive subjects with at least one episode of life-threatening hemoptysis that required BAE during a 5-y (January 2007 through December 2011) period were included. Life-threatening hemoptysis was defined as bleeding of $200 \mathrm{~mL}$ during $24 \mathrm{~h}, 100 \mathrm{~mL}$ daily during at least $3 \mathrm{~d}$, or a minor hemoptysis with hemodynamic instability. Recurring hemoptysis requiring BAE in a subject with previous embolization was included as a new hemoptysis event, unless it occurred within 1 month from the prior event (this was considered early recurrent bleeding). ${ }^{8}$

\section{Bronchial Arterial Embolization}

According to our institution's protocol, the platelet count, international normalized ratio, and activated partial thromboplastin were reviewed before angiography, and, if there were any coagulation disorders, they were corrected before the procedure. All procedures were performed by one of two interventional radiologists with $>10$ y of experience. The choice of catheter, microcatheter, and embolization materials was made at the discretion of the operating physician. Descending thoracic aortogram was acquired at the beginning of the procedure, followed by selective catheterization of bronchial arteries. If no abnormal bronchial arteries were identified, nonbronchial systemic arteries were selectively catheterized, depending on the known site of pulmonary disease. Target vessels were superselectively catheterized if stable cannulation could not be achieved or if more distal cannulation of the vessel was required to avoid important side branches, such as the anterior spinal artery. All abnormal vessels supplying the area of interest were embolized if technically possible. If there was no detectable underlying pulmonary abnormality, all bronchial arteries on the side of bleeding that could be catheterized were embolized. Contraindications to embolization were visualization of the anterior spinal branch (if it was not possible to advance the catheter beyond this point) or catheter instability. Pulmonary angiography was not routinely performed.

\section{Influenza Activity}

The internet search engine Google developed Google Flu Trends (GFT) in 2008, to estimate national and regional influenza incidence. GFT is highly correlated with

\section{QUICK LOOK}

\section{Current knowledge}

Hemoptysis is a potentially life-threatening condition requiring immediate intervention. Hemoptysis has been associated with influenza, infection, and climatic conditions, but no causal factors have been identified.

\section{What this paper contributes to our knowledge}

There was a significant association between severe hemoptysis requiring embolization and low monthly mean temperature and influenza activity. Other factors, such as atmospheric pressure, rainfall, and relative humidity, failed to show a significant association with the occurrence of life-threatening hemoptysis.

historical influenza-like illness conventional surveillance data and can detect regional outbreaks of influenza 7-10 d earlier than the existing United States Centers for Disease Control and Prevention surveillance system. ${ }^{9}$ GFT has been applied in many countries. ${ }^{10,11}$

For the purpose of this study, the weekly GFT estimates of influenza incidence in Catalonia, a northeastern region of Spain, were recorded (http://www.google.org/flutrends, Accessed January 10, 2013), and monthly estimates were calculated.

\section{Climatic Data Collection}

Meteorological data for the period from January 2007 to December 2011 were obtained from the Catalan meteorological agency (http://www.meteo.cat, Accessed December 13, 2012) for one weather station located in Badalona, $5 \mathrm{~km}$ away from our institution. Monthly mean values were obtained for maximum temperature, minimum temperature, mean temperature, atmospheric pressure, rainfall, relative humidity, and wind speed.

\section{Statistical Analysis}

A general multivariable additive seemingly causal model was applied, corresponding to a lagged variable autoregressive model with monthly mean temperature, lagged monthly mean temperature $(-1)$, and monthly mean influenza activity as exogenous variables, and the number of embolizations as the endogenous variable using the software Eviews-8 Enterprise Edition (IHS Global, Irvine, California). ${ }^{12}$ Multivariate equation estimation was performed by least squares method. 
Table 1. Characteristics of the 125 Subjects

\begin{tabular}{lc}
\hline \hline Age, median, mean $\pm \mathrm{SD}, \mathrm{y}$ & $60.6,58.2 \pm 17$ \\
Sex, $n(\%)$ & $92(74)$ \\
$\quad$ Male & $33(26)$ \\
Female & \\
Pathological condition, $n(\%)$ & $41(33)$ \\
$\quad$ Bronchiectasis & $25(20)$ \\
Cancer & $22(18)$ \\
COPD & $10(8)$ \\
Active tuberculosis & $27(21)$ \\
Idiopathic & \\
Embolizations per subject, $n(\%)$ & $115(92)$ \\
1 & $8(6)$ \\
2 & $2(2)$ \\
\hline 3
\end{tabular}

Table 2. Descriptive Statistic of Climatic Variables

\begin{tabular}{lc}
\hline \hline & $\begin{array}{c}\text { Mean } \pm \mathrm{SD} \\
(\text { minimum, maximum) }\end{array}$ \\
\hline $\begin{array}{l}\text { Atmospheric pressure, } \mathrm{mmHg} \\
\text { Temperature, }{ }^{\circ} \mathrm{C}\end{array}$ & $758.2 \pm 2.6(751.3,765.8)$ \\
$\quad$ Mean & $16.5 \pm 5.3(8.6,25.4)$ \\
$\quad$ Maximum & $19.5 \pm 4.8(11.5,27.6)$ \\
$\quad$ Minimum & $13.6 \pm 5.5(6.1,(23.0)$ \\
Rainfall, $\mathrm{L} / \mathrm{m}^{2}$ & $45.1 \pm 37.6(0.0,161.6)$ \\
Relative humidity, $\%$ & $68.5 \pm 4.61(60,82)$ \\
Wind speed, $\mathrm{m} / \mathrm{s}$ & $2.7 \pm 0.28(2.3,3.5)$ \\
\hline
\end{tabular}

\section{Ethical Considerations}

The research protocol was approved by the regional ethics committee (ethics committee for clinical research of the Hospital Germans Trias i Pujol).

\section{Results}

A total of 125 subjects who underwent 133 embolizations were included in the analysis. These subjects' characteristics can be seen in Table 1. Table 2 shows descriptive statistics for climatic variables.

Figure 1 shows the monthly time series evolution of the number of embolizations, mean temperature and influenza incidence between January 2007 and December 2011. Graphs of these series are not stationary, and temperature and influenza incidence have a clear seasonal component.

Correlogram of the time series of monthly mean relative humidity, wind velocity, and barometric pressure did not show significant peaks (Q-statistics) in the autocorrelation and partial correlation. This fact confirmed the stationary character of both series; therefore, they were not included in the multivariate time series analysis.

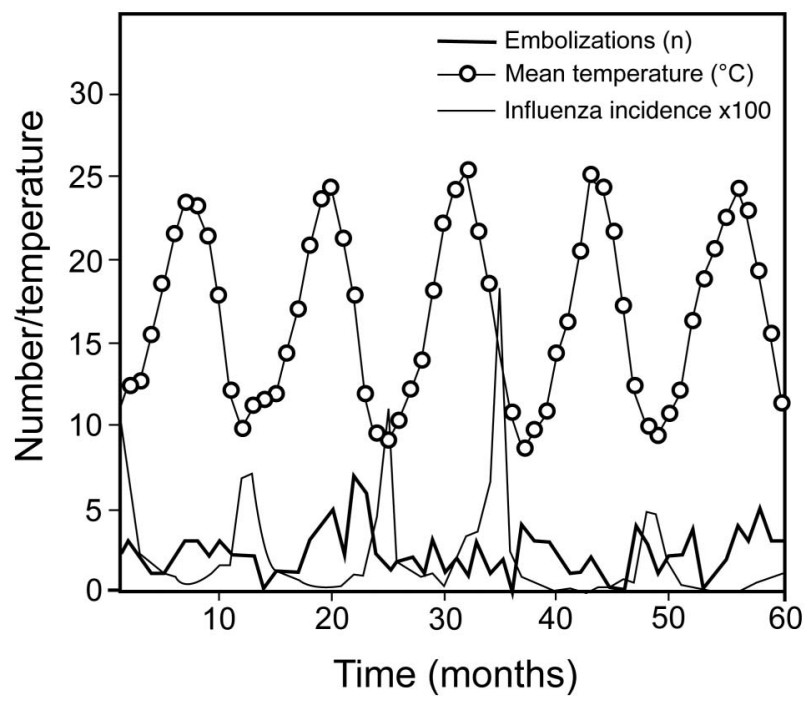

Fig. 1. Monthly time series evolution of number of embolizations, mean temperature, and influenza incidence between January 2007 and December 2011.

Table 3. Multivariable Lagged Variable Autoregressive Model Among Embolizations, Mean Temperature, and Influenza Activity

\begin{tabular}{lrc}
\hline \hline & Coefficient $\pm \mathrm{SE}$ & $P$ \\
\hline $\mathrm{C}$ & $1.83 \pm 0.98$ & .07 \\
Log (mean temperature) & $-1.49 \pm 0.54$ & .01 \\
Log (mean temperature $(-1))$ & $1.44 \pm 0.46$ & .00 \\
Log (influenza activity) & $-0.197 \pm 0.08$ & .02 \\
AR (1) & $0.03 \pm 0.16$ & .83
\end{tabular}

$\overline{\mathrm{R}^{2}=0.24 \text {; adjusted } \mathrm{R}^{2}}=0.17$; Durbin-Watson statistic $=2.10$; Akaike criterion $=1.52$; $\mathrm{F}$ statistic $=3.45 ;$ Provability $(\mathrm{F}$ statistic $)=0.015$.

$\mathrm{SE}=$ standard error

$\mathrm{C}=$ Coefficient

$\mathrm{AR}=$ Autoregressive

A general multivariable additive seemingly causal model was applied, corresponding to a lagged variable autoregressive model with monthly mean temperature, lagged monthly mean temperature $(-1)$, and monthly mean influenza activity as the exogenous variables, and the number of embolizations performed each month as the endogenous variable.

Table 3 presents the statistical results based on the model with $\mathrm{R}^{2}=0.17$. The Durbin-Watson statistic measures the serial correlation in the residuals. In general, if the DurbinWatson statistic is $<2$, there is evidence of positive serial correlation. In our case, the Durbin-Watson statistic was $>2$, which reflects the nonexistence of an autocorrelation problem. Akaike criterion was applied in model selection. We choose the length of lag by choosing the specification with the lowest value of Akaike criterion. All exogenous 
variables (monthly mean temperature, lagged monthly mean temperature $(-1)$, and monthly mean influenza activity) have a joint significant effect on $\log$ (embolizations) based on the F test $=3.45$ with a $P$ value $=.015$. The Jarque-Bera statistic was used to support the null hypothesis test of normal residues distribution (JarqueBera $=1.36, P=.50$ ). Model residues did not show heteroskedasticity or model residue variance changes $($ F test $=0.91, P=.50)$.

The estimation equation was:

$\log$ (embolization)

$$
\begin{aligned}
& =1.83-1.49 \times \log (\text { mean temperature }) \\
& +1.44 \times \log (\text { mean temperature }(-1)) \\
& -0.20 \times \log (\text { influenza activity }) \\
& +[\text { AR }(\text { Autoregressive })(1)=0.03]
\end{aligned}
$$

\section{Discussion}

This study provides evidence of an association between severe hemoptysis requiring BAE and low mean temperature and influenza activity in Badalona (Spain). Although this association is strong in the case of mean temperature, association in the case of influenza activity is lower. Other climatic factors, such as atmospheric pressure, rainfall, relative humidity, or wind speed, failed to show significant association with the occurrence of life-threatening hemoptysis.

Seasonality of hemoptysis has already been suggested. Our group, for example, reported that hemoptysis requiring BAE occurred with some monthly variation demonstrated by 2 peaks, with the first one occurring during April and the second one during November. ${ }^{3}$ On the other hand, Boulay and colleagues ${ }^{1}$ reported an increase in cryptogenic hemoptysis requiring hospitalization in late winter and early spring (peak in March). The same authors, in another article, reported that hemoptysis showed aggregates of clusters in winter. ${ }^{2}$

Association of hemoptysis with climatic factors has not been previously studied. Environmental triggering factors have been described in the literature as explanations for hemorrhagic events. Principally, a marked increase in hospital attendance due to epistaxis during colder days has been described, ${ }^{13}$ although Bray and colleagues, ${ }^{14}$ with a larger series, found no correlation between temperature, seasonal preponderance, and epistaxis. Apart from epistaxis, association of bleeding occurence with meteorological variations was found. ${ }^{15-17}$ Tahri et al ${ }^{16}$ found a higher risk of esophageal varices rupture during winter. Furthermore, they also found a significant correlation between the risk of bleeding and mean temperature, rainfall, and stormy weather. ${ }^{16}$ The occurrence of subarachnoid hemorrhage has also been associated with meteorological variations. ${ }^{15,17}$ Lejeune and colleagues ${ }^{15}$ found that aneurysmal bleeding was significantly associated with low maximal temperature, and Setzer et $\mathrm{al}^{17}$ demonstrated that atmospheric pressure changes of $>10 \mathrm{hPa}$ within $24 \mathrm{~h}$ were an independent predictor of clustering of patients with subarachnoid hemorrhage.

Some authors have suggested that one possible explanation for the increase in the number of patients with hemoptysis in winter could be the association of hemoptysis with acute infection. ${ }^{4,5}$ Smidt $^{18}$ reported that patients with cryptogenic hemoptysis often presented during times when influenza or pneumonia were common. Nevertheless, to the best of our knowledge, no study has previously evaluated how influenza season correlates with hemoptysis. One study suggested a potential synergistic mechanism by which other pathogens could interfere with the clinical course of influenza A infection. ${ }^{19}$ However, we did not analyze whether coexistence of respiratory infections with influenza could increase the risk of hemoptysis.

Identification of significant triggers of hemoptysis, such as low temperature or infection, could be useful for physicians to improve prevention measures and educational strategies in patients with those diseases that are more likely to produce hemoptysis, or those with a higher risk of recurrence.

This study has several limitations. First of all, we used a therapeutic technique as an indirect indicator of hemoptysis. Thus, not all patients with hemoptysis are included in this study. Those who died as a result of massive hemoptysis before BAE and those with mild or moderate hemoptysis that did not require BAE were not included in the study. Second, influenza activity was obtained from GFT, not by traditional surveillance systems. The estimates this model provides correlate very well with sentinel physician networks data, and can be made available 1 or 2 weeks earlier than Centers for Disease Control and Prevention surveillance reports. ${ }^{9}$ Nevertheless, although GFT is highly correlated with rates of influenza-like illness, it has a lower correlation with surveillance for laboratoryconfirmed influenza. ${ }^{20}$ Furthermore, some authors have concluded that GFT data may not provide reliable surveillance for influenza and should be interpreted with caution, and that current internet search query data are no substitute for timely local clinical and laboratory surveillance, or national surveillance based on local data collection. ${ }^{21}$

The main strength of this report is that all patients included in the study had confirmed severe hemoptysis, and other conditions that could be considered as hemoptysis (such as hematemesis) have been excluded. 


\section{Hemoptysis Is Associated With Low Temperature}

\section{Conclusions}

In summary, we show that there is a strong long running relationship between the number of embolizations performed and mean temperature. A weaker association of hemoptysis with influenza activity was also found. Confirmatory studies on the pattern of seasonal variation of hemoptysis shown in the present study are desirable, utilizing larger data sets.

\section{ACKNOWLEDGMENTS}

The authors thank Josep Roca MD for his critical revision of this paper.

\section{REFERENCES}

1. Boulay F, Berthier F, Sisteron O, Gendreike Y, Blaive B. Seasonal variation in cryptogenic and noncryptogenic hemoptysis hospitalizations in France. Chest 2000;118(2):440-444.

2. Boulay F, Sisteron O, Chevallier T, Blaive B. Predictable miniepidemics of spontaneous pneumothorax: haemoptysis too? Lancet 1998;351(9101):522.

3. Garcia-Olivé I, Fiz JA, Sanz-Santos J, Andreo F, Sánchez-Martínez E, Sampere J, et al. Temporal patterns in severe hemoptysis requiring bronchial artery embolization. Multidiscip Respir Med 2012;7(1):50.

4. Johnston RN, Lockhart W, Ritchie RT, Smith DH. Haemoptysis. Br Med J 1960;1(5173):592-595.

5. Lewis M, Kallenbach J, Kark P, Zalztman M, Hockman M, Zwi S. Severe haemoptysis associated with viral tracheitis. Thorax 1982; 37(11):869.

6. Adelman M, Haponik EF, Bleecker ER, Britt EJ. Cryptogenic hemoptysis: clinical features, bronchoscopic findings, and natural history in 67 patients. Ann Int Med 1985;102(6):829-834.

7. Sidhu M, Wieseler K, Burdick TR, Shaw DW. Bronchial artery embolization for hemoptysis. Semin Intervent Radiol 2008;25(3): 310-318.

8. Chun JY, Morgan R, Belli AM. Radiological management of hemoptysis: a comprehensive review of diagnostic imaging and bronchial arterial embolization. Cardiovasc Intervent Radiol 2010;33(2): 240-250.
9. Ginsberg J, Mohebbi MH, Patel RS, Brammer L, Smolinski MS, Brilliant L. Detecting influenza epidemics using search engine query data. Nature 2009;457(7232):1012-1014.

10. Valdivia A, López-Alcalde J, Vicente M, Pichiule M, Ruiz M, Ordobas M. Monitoring influenza activity in Europe with Google Flu Trends: comparison with the findings of sentinel physician networks; results for 2009-10. Euro Surveill 2010;15(29):pii=19621.

11. Kang M, Zhong H, He J, Rutherford S, Yang F. Using Google Trends for influenza surveillance in south China. PloS ONE 2013; 8(1):e55205.

12. Johansen S. Estimation and hypothesis testing of cointegration vectors in Gaussian vector autoregressive models. Econometrics 1991; 59:1551-1580.

13. Tomkinson A, Bremmer-Smith A, Craven C, Roblin DG. Hospital epistaxis admission rate and ambient temperature. Clin Otolaryngol Allied Sci 1995;20(3):239-240.

14. Bray D, Giddings CE, Monnery P, Eze N, Lo S, Toma AG. Epistaxis: are temperature and seasonal variations true factors in incidence? J Laryngol Otol 2005;119(9):724-726.

15. Lejeune JP, Vinchon M, Amouyel P, Escartin T, Escartin D, Christiaens JL. Association of occurrence of aneurysmal bleeding with meteorologic variations in the north of France. Stroke 1994;25(2): 338-341.

16. Tahri N, Amouri A, Fekih H, El-Euch F, Krichen MS. [Metereological conditions and esophageal varices rupture]. Ann Med Interne (Paris) 2003;154(8):509-514.

17. Setzer M, Beck J, Hermann E, Raabe A, Seifert V, Vatter H, Marquardt $\mathrm{G}$. The influence of barometric pressure changes and standard metereological variables on the occurrence and clinical features of subarachnoid hemorrhage. Surg Neurol 2007;67(3):264-272.

18. Smidt CM. Hemoptysis. Acta Oto-Laryngol 1957;47(3):265-269.

19. Bianco A, Parrella R, Esposito V, Mazzarella G, Sammarco ML, Brunese L, Ripabelli G. Severe A(H1N1)-associated pneumonia sequential to Clamidophila pneumoniae infection in healthy subject. In Vivo 2011;25(5):825-828

20. Ortiz JR, Zhou H, Shay DK, Neuzil KM, Fowlkes AL, Goss CH. Monitoring influenza activity in the United States: a comparison of the traditional surveillance systems with Google Flu Trends. PloS ONE 2011;6(4):e18687.

21. Olson DR, Konty KJ, Paladini M, Viboud C, Simonsen L. Reassessing Google Flu Trends data for detection of seasonal and pandemic influenza: a comparative epidemiological study at three geographic scales. PLoS Comput Biol 2013;9(10):e1003256. 